Research Article

\title{
Generation-3 Polyamidoamine Dendrimer-Silica Composite: Preparation and Cd(II) Removal Capacity
}

\author{
Augustus N. Ebelegi $\mathbb{D}^{D}$, Nimibofa Ayawei $\mathbb{D}^{D}$, Azibaola K. Inengite ${ }^{(D)}$, and Donbebe Wankasi \\ Department of Chemical Sciences, Niger Delta University, Amassama, Wilberforce Island, Bayelsa State, Nigeria \\ Correspondence should be addressed to Nimibofa Ayawei; ayawei4acad@gmail.com
}

Received 15 October 2020; Revised 4 December 2020; Accepted 16 December 2020; Published 28 December 2020

Academic Editor: Liviu Mitu

Copyright (c) 2020 Augustus N. Ebelegi et al. This is an open access article distributed under the Creative Commons Attribution License, which permits unrestricted use, distribution, and reproduction in any medium, provided the original work is properly cited.

Generation-3 polyamidoamine (PAMAM) dendrimer was implanted on silica to produce a very good adsorbent (G-3 PAMAMSGA). The composite was characterized and used for the removal of Cd(II) ions from aqueous solution. Kinetic data fit the Lagergren pseudo-second-order model and also follow the intraparticle diffusion kinetic model to an extent, which is an indication that the sorption process is controlled by both mechanisms: intraparticle/film layer and adsorption inside the pores/ crevices of the composite. Equilibrium sorption data of Cd(II) on G-3 PAMAM-SGA fit the Freundlich isotherm $\left(R^{2}=0.9993\right)$ which is indicative of multilayered adsorption that occurred on heterogeneous surfaces. The $\Delta G^{\circ}$ values for all temperatures studied were negative, which indicated a spontaneous and feasible process. The result implies that G-3 PAMAM-SGA is a promising adsorbent for microscale scavenging of $\mathrm{Cd}(\mathrm{II})$ ions in aqueous solutions.

\section{Introduction}

The term "heavy metal" describes naturally occurring elements that have atomic weights between 63.5 and $200.6 \mathrm{gmol}^{-1}$ and specific gravity more than $5.0 \mathrm{gcm}^{-1}$, and they are found in groups III-V on the periodic table [1]. Some heavy metals usually found within industrial wastewater streams include nickel $(\mathrm{Ni})$, lead $(\mathrm{Pb})$, chromium $(\mathrm{Cr})$, mercury $(\mathrm{Hg})$, zinc $(\mathrm{Zn})$, arsenic $(\mathrm{Ar})$, cadmium $(\mathrm{Cd})$, selenium $(\mathrm{Se})$, uranium $(\mathrm{Ur})$, silver $(\mathrm{Ag})$, and gold $(\mathrm{Au})$ [2].

Heavy metals are widely distributed in the environment due to their numerous uses in technological, industrial, domestic, agricultural, and medical fields as such their negative impact on environmental and human health is now a severe concern [3]. Investigations have shown that heavy metals are exceptionally toxic and can cause damaging effects on humans and other animals even at very low exposure levels because human beings and other animals do not have good elimination mechanisms for them [4]. Studies have shown that heavy metals could be emitted in their elemental or compound forms into the environment when triggered by natural or anthropogenic processes [5].
Humans ingest heavy metals through air, water, food, industrial products, and occupational exposure $[6,7]$. When heavy metals go into the human body, they migrate into the stomach which is an acidic medium and are converted to their stable oxidation states such as $\mathrm{Zn}^{2+}, \mathrm{Pb}^{2+}, \mathrm{Cd}^{2+}, \mathrm{As}^{2+}$, $\mathrm{As}^{3+}, \mathrm{Hg}^{2+}$, and $\mathrm{Ag}^{+}$, and these stable cations then interact with biomolecules such as enzymes and proteins to form strong and stable bonds which in turn inhibit the proper functioning of the biomolecules, thereby exhibiting poisoning effects to the human body [8]. Cd(II) ions are usually generated from a wide range of industrial processes such as metal smelting, alloy manufacturing, petroleum refining, solid mineral mining, and electroplating [9].

$\mathrm{Cd}(\mathrm{II})$ ions are easily dispersed into the environment through natural emissions/bioaccumulation processes which happen in some plants and animals [10]. Some other well-known means of exposure to $\mathrm{Cd}(\mathrm{II})$ ions include inhalation of cigarette smoke and intake of cadmium-contaminated food and water. Reports have it that cadmium is very poisonous even at very small concentrations because it causes damage to the human body cells $[11,12]$. Some conventional procedures for decontaminating aqueous 
systems polluted with heavy metal ions include chemical precipitation, ion exchange, coagulation/flocculation, ultrafiltration, electrochemical treatment, electrodialysis, and adsorption.

Adsorption is a renowned, straightforward, cost-effective, and proficient means of eliminating heavy metal ions from aqueous systems via a range of adsorbents such as fly ash, bentonite, metal-organic frameworks, layered double hydroxides, and many other carbon-based and agricultural waste materials [13]. In recent times, silica-based adsorbents have attracted attention in wastewater treatment because they possess special inherent properties such as chemical inertness, large pore sizes, large surface area, and susceptibility to functionalization to meet selectivity criteria for specific pollutants [14].

Studies have shown that when cross-linked polymeric resins are immobilized on silica by means of covalently attached functional groups, inorganic-organic hybrid adsorbents are formed [15]. One of such is the polyamidoamine (PAMAM) dendrimer-silica hybrid wherein the immobilization of PAMAM dendrimer on silica results in the versatility of PAMAM-functionalized silica materials as adsorbents. Owing to its elemental composition, PAMAM dendrimer contains very many forms of oxygen and nitrogen atoms that facilitate effective chelation and complexation reactions with metal ions, and they also enhance the chemical modification of the polymer for the purposes of improved adsorption capacity and selectivity $[16,17]$. Thus, the presence of numerous amide and primary amine groups creates the especial capability for PAMAM-silica composites to bind on various molecules in aqueous and nonaqueous media [18-20].

Thus, surface modification of adsorbent materials is enticing as a contemporary research component for the advance of low-cost procedures for the removal of heavy metal ions from aqueous systems [21].

In this study, functionalized generation-3 polyamidoamine dendrimer molecules were immobilized on silica using the graft to approach wherein the full dendritic character of the dendrimer is maintained. Consequently, a dendrimer-silica composite with unique physicochemical properties was fabricated (see Section 3.1). The prepared adsorbent was then tested for its sequestration of Cd(II) ions in aqueous solution under optimized reaction conditions of contact time, $\mathrm{pH}$, initial concentration, and temperature.

\section{Materials and Method}

2.1. Synthesis of G-3 PAMAM-Functionalized Silica. All chemicals used during this study were of analytical grade; they include generation-3 polyamidoamine (PAMAM) dendrimers (with ethylenediamine core), succinic anhydride, 3-aminopropyltriethoxysilane (APTES), cadmium nitrate salt, and chromatographic-grade silica gel (particle size of 240-425 mesh, pore size of $15 \mathrm{~nm}, \mathrm{pH}$ of 7, and pore volume of $1.15 \mathrm{~cm}^{3} / \mathrm{g}$ ) acquired from Sigma-Aldrich, South Africa, and $N$-(3-dimethylaminopropyl)- $N^{\prime}$-ethylcarbodiimide hydrochloride produced by Thermo Fisher Scientific, Belgium.
The linking agent 3-aminopropyltriethoxysilane (APTES) was grafted on silica gel using similar methods as described by Acres et al. [22]. Silica gel (30 g) was activated by oven-drying for 2 hours at a temperature of $130^{\circ} \mathrm{C}$. The activated silica $(20 \mathrm{~g})$ was refluxed at $115^{\circ} \mathrm{C}$ for 6 hours in a mixture composed of $10 \%$ APTES and $100 \mathrm{~mL}$ anhydrous toluene. The ensuing product obtained is the amino-functionalized silica which was consequently separated from the solution by centrifugation at $4000 \mathrm{rpm}$ for $10 \mathrm{~min}$. The amino-functionalized silica was washed using water and ethanol alternatively in order to remove excess reagents, with the very last wash done with ethanol after which the product was oven-dried at $110^{\circ} \mathrm{C}$ for 1 hour. The product (amino-functionalized silica) was then stored in a preclean sample storage bottle for later use.

Another intermediate product (succinic acid-terminated generation-3 PAMAM dendrimer) was prepared using the method of Jiang et al [23]. The succinic acid-terminated generation-3 PAMAM dendrimers were prepared by dissolving approximately $3.7 \mathrm{~mL}$ of G-3 PAMAM dendrimer and $3.1 \mathrm{~g}$ of succinic anhydride in separate $50 \mathrm{~mL}$ volumes of dimethyl sulfoxide (DMSO). Both solutions were then transferred into a round-bottom flask and refluxed for 12 hours at a temperature of $80^{\circ} \mathrm{C}$ followed by dialysis with deionized water over 3 days (deionized water was replaced every 6 hours). The succinic acid-terminated generation-3 PAMAM was withdrawn from the dialysis setup by means of a micropipette and stored for further use.

The aim of this phase of synthesis was to synthesize a G-3 PAMAM dendrimer-functionalized silica (G-3 PAMAMSGA) relying on the reaction between the succinic acid terminal of the succinic acid-terminated generation-3 PAMAM dendrimer and the amine terminal of the aminofunctionalized silica. The method of Shi et al. [24] was adopted. Approximately $20 \mathrm{~g}$ of both intermediate products (i.e., silica grafted with APTES and succinic acid-terminated generation-3 PAMAM dendrimer) was added into a $250 \mathrm{~mL}$ round-bottom flask containing $75 \mathrm{~mL}$ methanol. The coupling agent $N$-(3-dimethylaminopropyl)- $N^{\prime}$-ethylcarbodiimide hydrochloride (EDC) $(\approx 5 \mathrm{mg})$ [25] was added to the flask and the whole mixture was refluxed at $90^{\circ} \mathrm{C}$ for 12 hours. The product was separated from the solution by centrifugation at $4000 \mathrm{rpm}$ for about 10 minutes, and thereafter, it was washed three times with ethanol and ovendried at $110^{\circ} \mathrm{C}$ for 1 hour. The end product is the G-3 PAMAM-functionalized silica (G-3 PAMAM-SGA).

2.2. Characterization of the Adsorbent. The synthesized composite (G-3 PAMAM-SGA) and one of its precursor materials (unmodified silica) were characterized using Fourier transform infrared (FTIR) spectrometer (Spectrum Two, Perkin Elmer Instruments, USA) in order to determine the associated functional groups, Micromeritics TRISTAR II 3020 analyzer (Micromeritics Instrument Corporation, USA) was used to determine the surface area and porosity, thermogravimetric analyzer (PerkinElmer TGA 4000, Perkin Elmer Instruments, USA) was used for thermogravimetric analysis (TGA) in order to determine the material's 
thermal stability, and the scanning electron microscope (SEM) (Zeiss Auriga Field Emission) was used for the determination of the adsorbent's surface morphology.

2.3. Adsorption Study. The stock of the adsorbate solution $(1000 \mathrm{~g} / \mathrm{L})$ was prepared using cadmium nitrate salt $\left(\mathrm{Cd}\left(\mathrm{NO}_{3}\right)_{2}\right)$, and working solutions were then prepared from the stock by serial dilution. Batch adsorption of Cd(II) ions was carried out in triplicate using G-3 PAMAM-SGA as an adsorbent with the aim of determining the effects of operation parameters such as contact time, concentration, $\mathrm{pH}$, and temperature.

The adsorption procedure was performed as follows: $20 \mathrm{mg}$ of adsorbent material was added to $20 \mathrm{~mL}$ adsorbate solution of specific concentration in plastic centrifuge bottles. The adsorbate/adsorbent mixture was then placed in an orbital shaker operated at $200 \mathrm{rpm}$ until equilibrium was achieved. The solution's $\mathrm{pH}$ was adjusted by either $0.1 \mathrm{M} \mathrm{HCl}$ or $0.1 \mathrm{M} \mathrm{NaOH}$ when necessary. At equilibrium, the centrifuge tubes were withdrawn, followed by centrifugation at $4000 \mathrm{rpm}$ for $10 \mathrm{~min}$. The amount of Cd(II) ions remaining in the solution was determined using a flame atomic absorption spectrophotometer (F-AAS, Shimadzu AA-7000, Japan).

2.4. Desorption Study. A desorption experiment was carried out on $20 \mathrm{mg}$ of the previously used adsorbent. Adsorbate ions (Cd(II)) that were primarily adsorbed onto the adsorbent were desorbed by shaking in $20 \mathrm{~mL} 0.5 \mathrm{M}$ nitric acid at $220 \mathrm{rpm}$ for 10 minutes. The plastic centrifuge bottles were removed from the shaker and centrifuged at $3500 \mathrm{rpm}$ for 10 minutes. The amount of $\mathrm{Cd}(\mathrm{II})$ ion left in the solution was determined using atomic adsorption spectrometry.

The adsorbent was washed twice with $0.5 \mathrm{M}$ nitric acid and last of all with deionized water before the second round of reuse experiment (second cycle). The reuse investigation was carried out for three cycles.

2.5. Data Management. The adsorption capacity $\left(q_{\mathrm{e}}\right)$ and removal capacity $(R \%)$ of $\mathrm{Cd}(\mathrm{II})$ ions by G-3 PAMAM-SGA were calculated using the following equations:

$$
\begin{gathered}
q_{e}=\frac{\left(C_{0}-C_{e}\right) V}{M}, \\
R(\%)=\left(\frac{C_{0}-C_{e}}{C_{0}}\right) \times 100,
\end{gathered}
$$

where $C_{0}$ and $C_{e}(\mathrm{mg} / \mathrm{L})$ are the initial and equilibrium concentrations of $\mathrm{Cd}(\mathrm{II})$ ions in solution, $V$ is the volume of adsorbate solution used $(\mathrm{mL})$, and $M$ is the mass of adsorbent used for the experiment.

Three kinetic isotherm models, pseudo-first-order (PFO) [26] (equation (2)), pseudo-second-order (PSO) [27] (equation (3)), and Weber-Morris intraparticle diffusion (IPD) [28] (equation (4))], were used in describing the effect of time data:

$$
\begin{aligned}
& q_{t}=q_{e}\left(1-e^{-k_{2} t}\right) \cdot k 1, \\
& q_{t}=\frac{q_{e}^{2} k_{2} t}{1+q_{e} k_{2} t} \\
& q_{e}=k_{I P D} t^{1 / 2}+C,
\end{aligned}
$$

The symbols $q_{\mathrm{e}}$ and $q_{\mathrm{t}}$ are the amounts of $\mathrm{Cd}(\mathrm{II})$ adsorbed $(\mathrm{mg} / \mathrm{g})$ on the adsorbent (G-3 PAMAM-SGA) at equilibrium and time $t$, respectively, and $k_{1}\left(\mathrm{~min}^{-1}\right), k_{2}(\mathrm{~g} / \mathrm{g} /$ $\mathrm{min})$, and $k_{\mathrm{IPD}}\left(\mathrm{g} / \mathrm{g} \mathrm{min}^{1 / 2}\right)$ are the rate constants of the PFO, PSO, and IPD, respectively, while $C(\mathrm{mg} / \mathrm{g})$ is the amount of Cd(II) adsorbed on the adsorbent surfaces.

Equilibrium data at $294 \mathrm{~K}$ were calculated using Langmuir [29] (equation (5)), Freundlich [30] (equation (6)), and Flory-Huggins [31] (equation (7)):

$$
\frac{C_{e}}{q_{e}}=\frac{1}{q_{m} K_{e}}+C_{e} / q_{m},
$$

where $C_{e}$ is the concentration of adsorbate at equilibrium $\left(m g g^{-1}\right)$ and $K_{L}$ is the Langmuir constant related to adsorption capacity $\left(m g g^{-1}\right)$.

$$
\log q_{e}=\log K_{F}+\frac{1}{n} \log C_{e},
$$

where $K_{F}$ is the adsorption capacity $(L / \mathrm{mg})$ and $1 / n$ is the adsorption intensity and it also indicates the relative distribution of the energy and the heterogeneity of the adsorbate sites.

Flory-Huggins isotherm describes the degree of surface coverage characteristics of the adsorbate on the adsorbent [31].

The linear form of the Flory-Huggins equation is expressed as follows:

$$
\ln \left(\frac{\theta}{C_{o}}\right)=\ln K_{F H}+n \ln (1-\theta),
$$

where $\theta$ is the degree of surface coverage, $n$ is the number of adsorbates occupying adsorption sites, and $K_{F H}$ is the Flory-Huggins equilibrium constant $\left(\mathrm{Lmol}^{-1}\right)$.

Thermodynamic parameters such as enthalpy change and entropy change were calculated using van't Hoff equation [14] (equation (8)) and Gibbs free energy of adsorption was evaluated using equation (9):

$$
\begin{aligned}
& \ln K=\frac{\Delta S}{R}-\frac{\Delta H}{R T}, \\
& \Delta \mathrm{G}^{*}=\Delta \mathrm{H}^{*}-\mathrm{T} \Delta \mathrm{S}^{*},
\end{aligned}
$$

where $T$ is the temperature $(\mathrm{K})$ and $R$ is the ideal gas constant

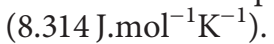

The linear form of the modified Arrhenius expression was applied to the experimental data to evaluate the activation energy $\left(E_{\mathrm{a}}\right)$ and sticking probability $S *$ as shown in the following equation [32]: 


$$
\operatorname{In}(1-\theta)=\ln S^{*}+\frac{E_{a}}{R T},
$$

where $\theta$ is the degree of surface coverage.

\section{Results and Discussions}

3.1. Characterization Results. A graphic representation for the synthesis of G-3 PAMAM-functionalized silica (G-3 PAMAM-SGA) adsorbent is shown in Figure 1. Pristine silica and G-3 PAMAM dendrimer were pretreated independently before both moieties were condensed to get the ultimate adsorbent. APTES was initially grafted on activated silica gel using surface hydroxyl groups ensuing in an amino$\left(-\mathrm{NH}_{2}-\right)$ functionalized silica. Subsequently, generation-3 PAMAM dendrimers were functionalized with succinic anhydride to form the carboxylic acid-terminated dendrimer. Lastly, amino-functionalized silica moieties were combined with the acid- (-COOH-) terminated generation3 PAMAM dendrimers using a linking agent $N$-(3-dimethylaminopropyl)- $N^{\prime}$-ethylcarbodiimide hydrochloride (EDC) [26]. Literature has shown that surface coverage of silica with an organic compound leads to an increase in the $\mathrm{pH}$ at the point of zero charge $\left(\mathrm{pH}_{\mathrm{pzc}}\right)$ from 2.1 to higher values [32]. The $\mathrm{pH}$ at point of zero charge $\left(\mathrm{pH}_{\mathrm{pzc}}\right)$ of $\mathrm{G}-3$ PAMAM-SGA is observed to be 3.1, which also corroborates the successful immobilization of the G-3 PAMAM dendrimer on silica. This means the surfaces of the dendrimerfunctionalized silica composite become predominantly negatively charged with the $\mathrm{pH}$ value of above 3.1.

Other evidences of the successful synthesis of the G-3 PAMAM-SGA are shown in results of the physical and chemical properties (see Table 1 and Figure 2).

The $\mathrm{N}_{2}$ adsorption/desorption isotherm (not shown) implied a typical type IV isotherm, which points to the mesoporous nature of G-3 PAMAM-SGA. BET surface area was $16.9 \mathrm{~m}^{2} / \mathrm{g}$ with a pore width of $17.4 \mathrm{~nm}$ which is larger than that for some previously reported silica-based adsorbents [34]. This large pore width would have facilitated the fast uptake of large adsorbate molecules from aqueous solutions by means of pore-filling mechanisms [33]. The FTIR spectra of the unmodified silica and G-3 PAMAM SGA adsorbents are shown in Figure 2(a). The distinct stretching peaks of the silanol group ( $\mathrm{Si}-\mathrm{O}-\mathrm{Si}$ ) were obvious at around 1060 and $800 \mathrm{~cm}^{-1}$ [35], while the obvious peak at $1630 \mathrm{~cm}^{-1}$ is ascribable to the newly added amide group. The TGA spectra shown in Figures 2(b)-2(d) reveal two major thermal transitions for both the unmodified silica and the synthesized adsorbent (G-3 PAMAM-SGA) as the temperature was rapidly increased from 40 to $900^{\circ} \mathrm{C}$. The first thermal transition was observed below $150^{\circ} \mathrm{C}$ for both materials (Figures 2(b)-2(c)) and this was attributed to the loss of physisorbed water molecules within layers of the backbone silica material [35]. The second thermal transition was observed at $665^{\circ} \mathrm{C}$ for pristine silica with a weight loss of $3.5 \%$ (Figure 2(d)), while it was observed at a lower temperature $\left(565^{\circ} \mathrm{C}\right)$ for the synthesized adsorbent (Figure 2(d)). The massive weight loss exhibited by G-3 PAMAM SGA at low temperature could be inferred as a confirmation of the presence of APTES and PAMAM groups which were more labile than the backbone silica material. Consequently, the weight losses at this second thermal transition were ascribed to the endothermic breakdown of surface hydroxyl groups on the unmodified silica and G-3 PAMAM SGA. The SEM images revealing pre- and postadsorption of Cd (II) ions onto G-3 PAMAM SGA are shown in Figures 2(e)-2(f). Figure 2(e) exhibits the clear surface image of the preadsorption SEM while the postadsorption surface SEM images (Figure 2(f)) show shinny agglomerated surfaces due to the presence of the adsorbed Cd(II) ions.

3.2. Effect of Time on Cd(II) Adsorption. The result of Cd(II) adsorption trend on the G-3 PAMAM SGA as time varied is shown in Figure 3(b). From this, it was observed that the uptake rate was quite fast at the beginning of the experiment to the initial $100 \mathrm{~min}$ when the adsorption-desorption rate became stable and equilibrium was achieved at approximately $180 \mathrm{~min}$. The initial fast adsorption rate was attributed to adsorption on the several available surface adsorption sites and filling of the pore/cavities by adsorbate ions in solution. Subsequently, not much significant Cd(II) adsorption was feasible because vacant adsorption sites have been filled, and accordingly, equilibrium is said to have been attained. From this experiment, the time for equilibrium attainment by the adsorbate (G-3 PAMAM SGA) was observed to be $180 \mathrm{~min}$ (see Figure 3(a)). In order to establish the mechanism of Cd(II) adsorption by G-3 PAMAM SGA, the effect of time data was fitted to three adsorption kinetic models: the pseudo-first-order, pseudo-second-order, and the intraparticle kinetic models. The results are shown in Table 2.

The results represented in Table 2 showed a poor fitting correlation coefficient of $r^{2}<0.6671$ in the pseudo-first-order kinetic model. In contrast to the experimental data, the fitting for the pseudo-second-order kinetic model was better correlated $\left(r^{2}>0.991\right)$ (figure not shown). Hence, the experimental data fitted the pseudo-second-order kinetic model better than the pseudo-first-order kinetic model and gave more insight into the mechanism of the adsorption process. This fitting connotes that Cd(II) removal mechanism was for the most part electrostatic interactions between the Cd(II) ions and the active functional groups on the G-3 PAMAM SGA composite because it has been shown that the pseudo-second-order kinetic model is similar to the universal rate law for chemical reactions [36-38]. The wellknown intraparticle diffusion kinetic model by Weber-Morris [29] has been used to determine whether an adsorption process occurs at the surface of an adsorbent or within its pores/partitions. Reports have it that the IPD model parameter $C(\mathrm{mg} / \mathrm{g})$ is a means of estimating surface adsorption, this means when the numerical value of " $C$ " is equal to the experimental value " $q_{\mathrm{e}}$," then the adsorption process is mainly controlled by surface adsorption, and the remaining part of the adsorption process is attributed to pore filling/portioning within the adsorbent [39]. Thus, the $C$ value in Table 2 implied approximately $41.75 \%$ was due to 


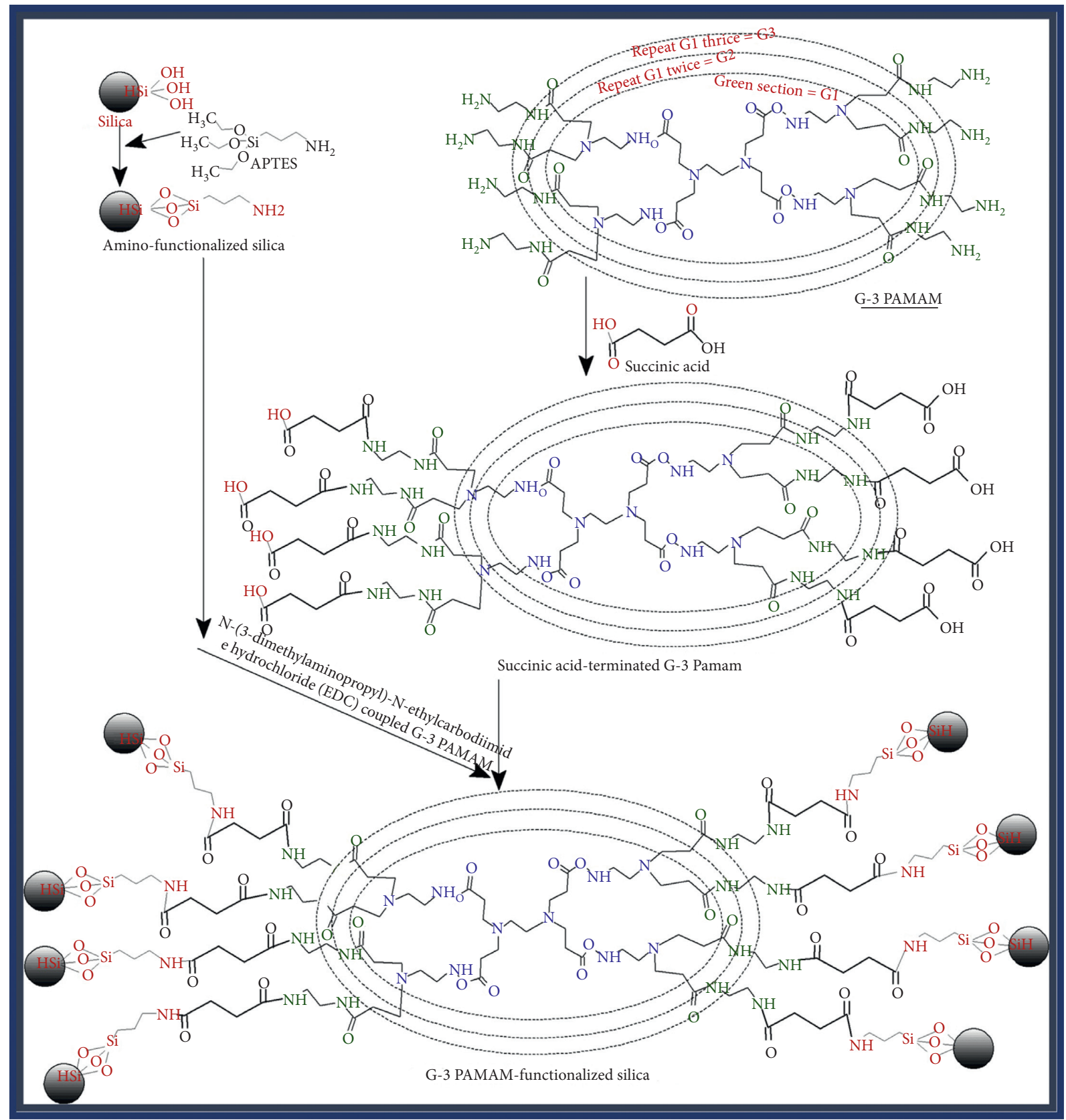

FIgURE 1: Schematics for the synthesis of G-3 PAMAM SGA [33].

TABle 1: Physicochemical parameters of the synthesized G-3 PAMAM SGA adsorbent.

\begin{tabular}{lcccc}
\hline Adsorbent & pHpzc & BET surface area $\left(\mathrm{m}^{2} / \mathrm{g}\right)$ & Pore size $\left(\mathrm{cm}^{2} / \mathrm{g}\right)$ & Pore width $(\mathrm{nm})$ \\
\hline G-3 PAMAM SGA & 3.1 & 16.9 & 0.073 & 17.4
\end{tabular}

surface adsorption and $58.25 \%$ was due to pore filling/ partitioning.

3.3. Effect of $p H$ on $C d(I I)$ Adsorption. Establishing the performance of a novel adsorbent to $\mathrm{pH}$ variations within aqueous systems is imperative in predicting the worth of such an adsorbent. Investigations have shown that $\mathrm{pH}$ has a direct effect on the magnitude of charge density surrounding adsorbents and adsorbates, and this eventually directs the degree of adsorption [36]. Consequently, the effect of $\mathrm{pH}$ on Cd(II) adsorption onto G-3 PAMAM SGA was examined as $\mathrm{pH}$ varied from 3 to 7 , and the results are shown in Figure 3(b). It was observed that the absorption increased with an increase in the $\mathrm{pH}$ of the adsorbate solution. The observed drift can be explained in terms of the $\mathrm{pH}$ at point of zero charge (pHpzc) of G-3 PAMAM SGA ( $\mathrm{pHpzc}=3.1$ ). Below the observed pHpzc, the adsorbent's surfaces which 


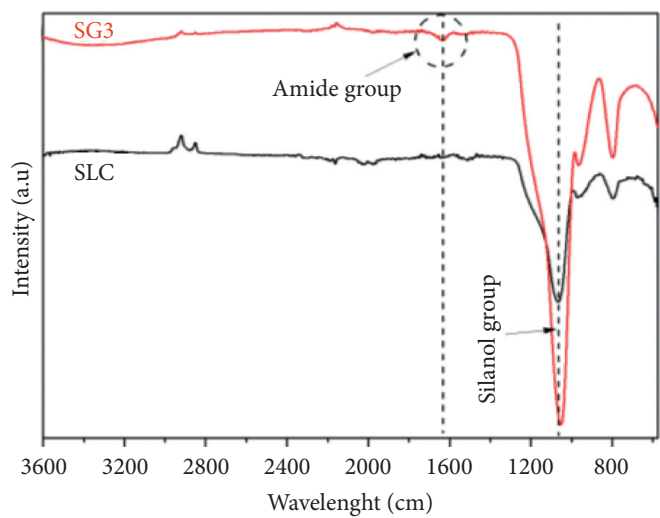

(a)

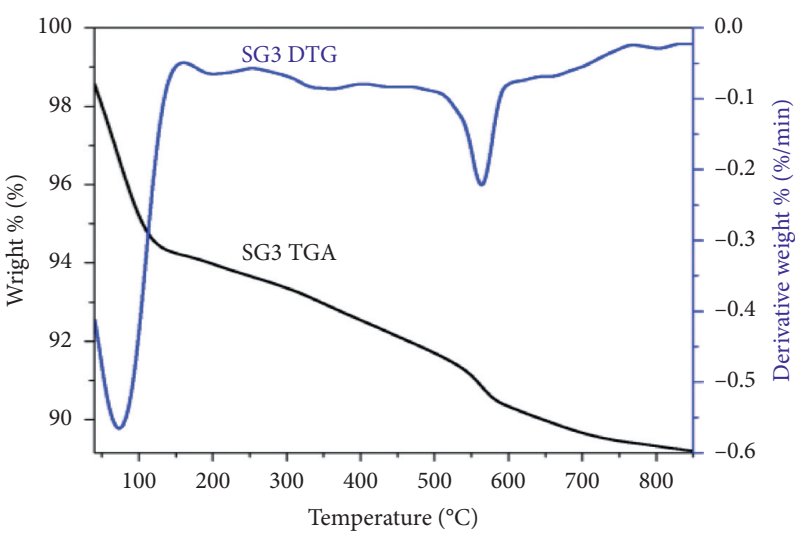

(c)

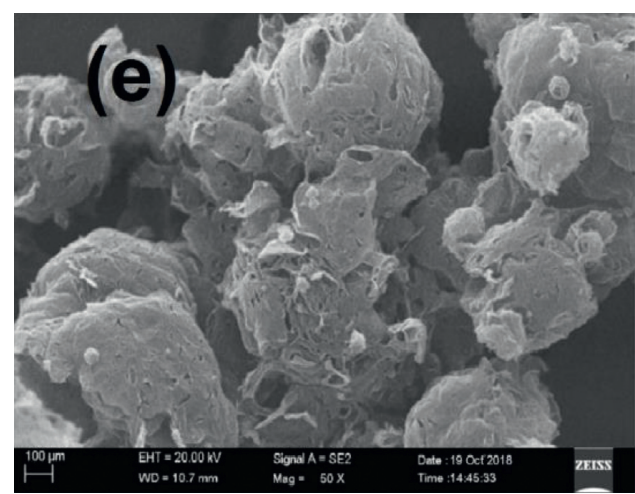

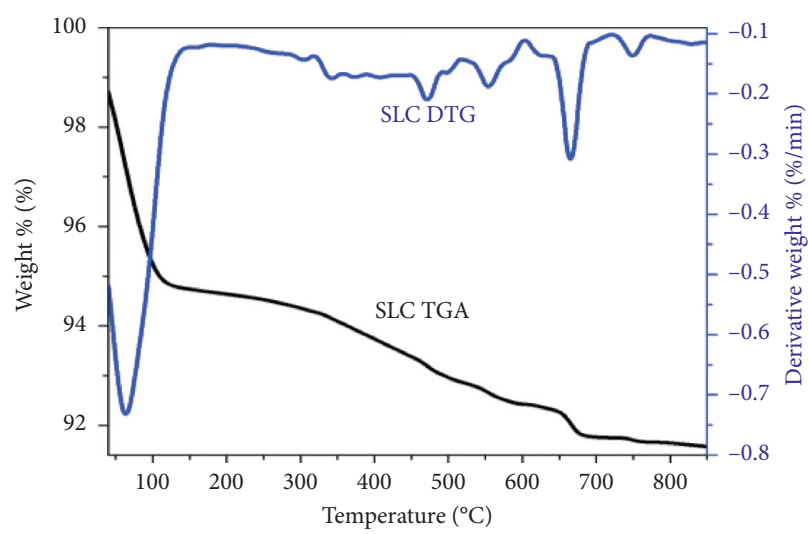

(b)

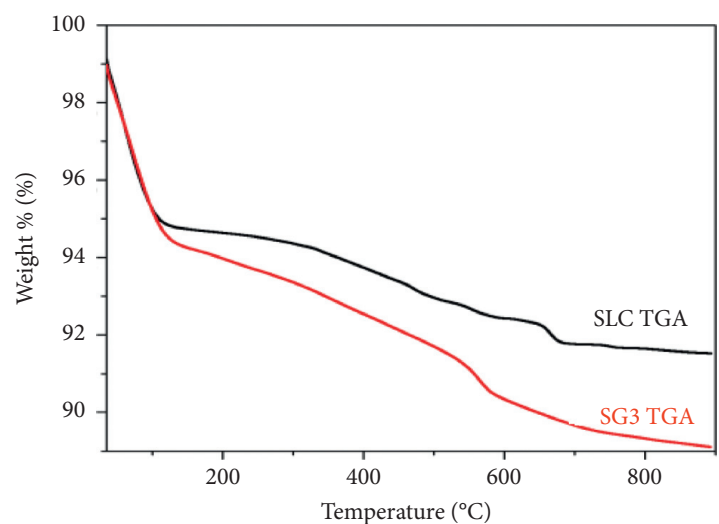

(d)

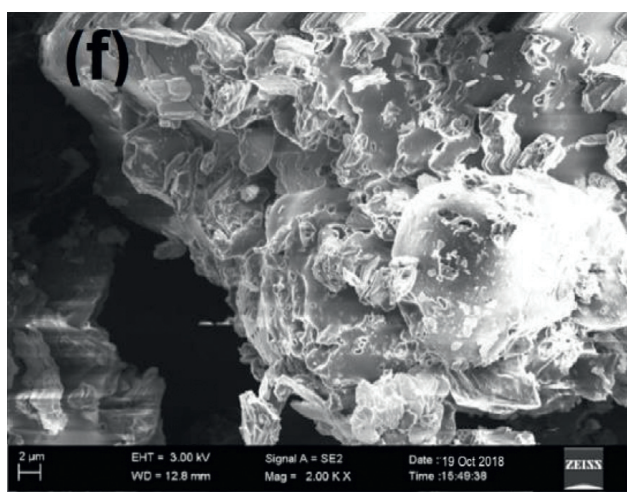

FIgURE 2: (a) FTIR spectra of pristine silica and G-3 PAMAM SGA; TGA and DTA spectra of (b) pristine silica and (c) G-3 PAMAM SGA; (d) comparison of TGA spectra for pristine silica and G-3 PAMAM SGA; SEM micrograph of G-3 PAMAM SGA (e) before and (f) after $\mathrm{Cd}^{2+}$ adsorption.

bear anionic functional groups such as hydroxyl and carbonates are blocked by protonation making them uncharged, so the removal of Cd(II) ions is mostly feasible via pore filling due to marginal electrostatic attraction. Conversely, with increasing $\mathrm{pH}$, the adsorbent's surface adsorption sites become progressively deprotonated and negatively charged. This leads to additional electrostatic interactions between the $\mathrm{Cd}$ (II) ions in the solution and the charged surface functional groups on the adsorbent, and as a result, progressively more $\mathrm{Cd}(\mathrm{II})$ adsorption was recorded. From the experimental result, optimum adsorption was observed at $\mathrm{pH}=5$.
3.4. Effect of Concentration of Adsorbate Solution and Temperature on Adsorption Trend. The result of the effect of varying $\mathrm{Cd}$ (II) concentration on G-3 PAMAM SGA adsorption is represented as the adsorption trend plots in Figure 4. It was observed that an increase in $\mathrm{Cd}(\mathrm{II})$ ion concentration in solution resulted in higher uptake by G-3 PAMAM. This trend was also observed for the various temperatures investigated: $293 \mathrm{~K}, 303 \mathrm{~K}$, and $313 \mathrm{~K}$ (Figure 4). Analogous trend has been reported in the literature [40]. This could be attributed to the fact that, at some point in adsorption, the transportation of adsorbate ions between the external surface film and internal cavities of the 


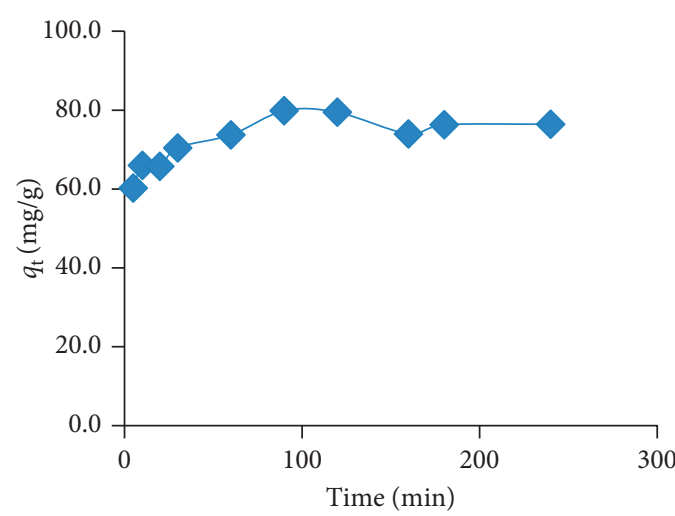

(a)

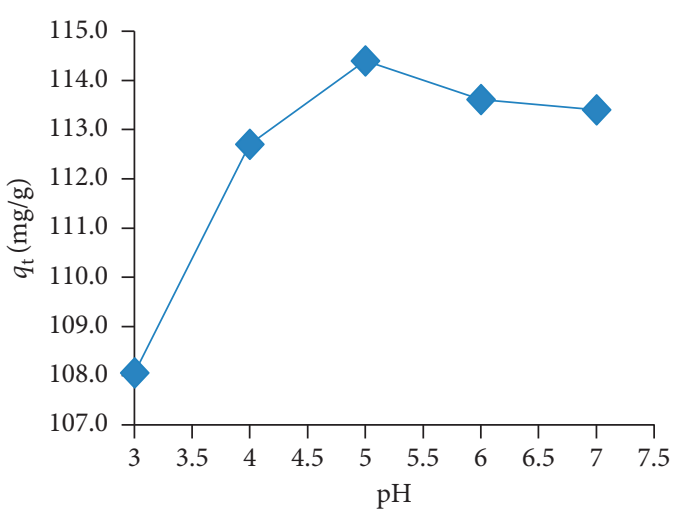

(b)

Figure 3: Adsorption trend for Cd (II) on G-3 PAMAM SGA as time (a) and pH (b) increased.

TABle 2: Kinetic model parameters for Cd(II) adsorption.

\begin{tabular}{lcc}
\hline Kinetic model & Parameter & Cd(II) \\
\hline & $q_{\mathrm{e}}\left(\mathrm{mg}^{-1}\right)$ & 37.21 \\
PFO & $k_{1}\left(\mathrm{~min}^{-1}\right)$ & 0.083 \\
& $r^{2}$ & 0.637 \\
PSO & $q_{\mathrm{e}}\left(\mathrm{mg}^{-1}\right)$ & 32.546 \\
& $k_{2}\left(\mathrm{~g} \mathrm{mg}^{-1} \cdot \mathrm{min}^{-1}\right)$ & 0.8182 \\
& $r^{2}$ & 0.9912 \\
IPD & $C\left(\mathrm{mg}^{-1}\right)$ & 19.64 \\
& $k_{i}\left(\mathrm{~g} \mathrm{~g}^{-1} \cdot \mathrm{min}^{1 / 2}\right)$ & 1.524 \\
PPA from IPD & $r^{2}$ & 0.7621 \\
PSA from IPD & $\%$ & 41.75 \\
Experimental $q_{\mathrm{e}}$ & $\%$ & 58.25 \\
\hline
\end{tabular}

PFO: pseudo-first-order model; PSO: pseudo-second-order model; IPD: intraparticle diffusion model; PPA: predicted pore adsorption from IPD; PSA: predicted surface adsorption from IPD.

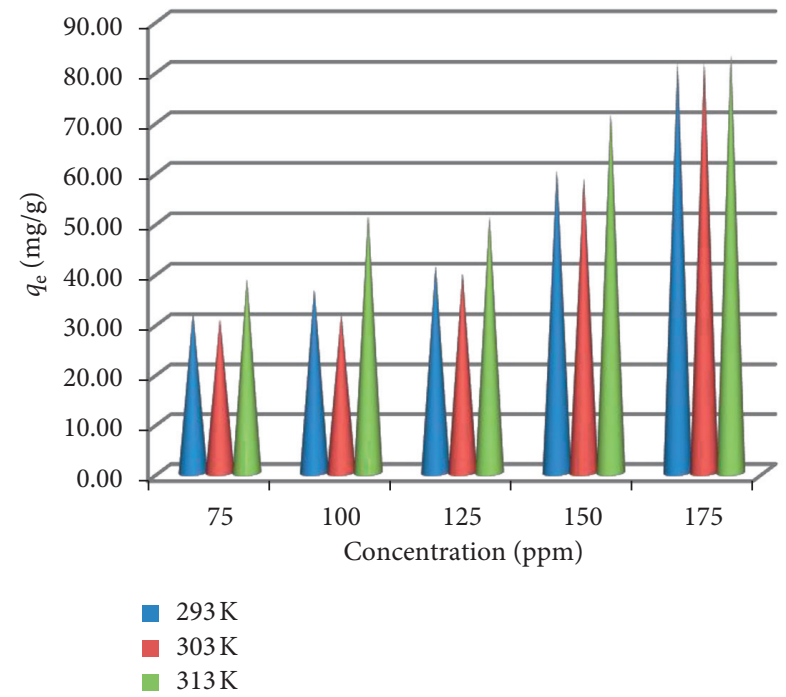

FIGURE 4: Effect of initial concentration and operating temperature on the adsorption of Cd(II) ions onto G-3 PAMAM SGA. adsorbent equilibrates, as such adsorbate ions may not be able to migrate across the boundary, but increasing the concentration of adsorbate solution reenacts this transboundary drift into the pores and cavities of the adsorbent and this may have facilitated multilayer adsorption. Similar findings have been reported in the literature [38]. The figure also showed that an increase in temperature resulted in a significant increase in adsorbate uptake, which may be ascribed to increase the mobility of adsorbate ions that facilitated the transboundary movement of adsorbate ions at higher temperatures, and thus, the process could be adjudged to be endothermic [41].

3.5. Equilibrium/Thermodynamics Studies. To facilitate a better description of the adsorption mechanism, the equilibrium data at $293 \mathrm{~K}$ were fitted to three adsorption isotherm models: the Langmuir, Freundlich, and Flor$y$-Huggins models. Comparison of model parameters in Table 3 showed that the experimental data fitted the Freundlich adsorption isotherm model better than the 
TABLE 3: Adsorption isotherm model parameters for Cd(II).

\begin{tabular}{lcc}
\hline Adsorption isotherm model & Parameter & $\mathrm{Cd}(\mathrm{II})$ \\
\hline \multirow{3}{*}{ Langmuir } & $Q_{\mathrm{o}}(\mathrm{mg} / \mathrm{g})$ & 28.49 \\
& $\beta$ & 0.02 \\
& $r^{2}$ & 0.980 \\
Freundlich & $1 / n$ & 5.986 \\
& $k_{\mathrm{f}}$ & 1.787 \\
Flory-Huggins & $R^{2}$ & 0.9993 \\
& $K_{H}$ & 0.539 \\
Experimental $Q_{\mathrm{o}}(\mathrm{mg} / \mathrm{g})$ & $n$ & 1.581 \\
& $R^{2}$ & 0.983 \\
\end{tabular}

Flory-Huggins and Langmuir models. The Freundlich model had a correlation coefficient $\left(r^{2}\right)$ closer to unity (0.999) while the Flory-Huggins model $\left(r^{2}=0.983\right)$ and Langmuir model had the least $\left(r^{2}=0.980\right)$. The correlation of the experimental data to the Freundlich adsorption isotherm model implies that the adsorption of $\mathrm{Cd}(\mathrm{II})$ on G-3 PAMAM SGA might have occurred on sites of unequal affinity for the $\mathrm{Cd}(\mathrm{II})$ ions as such there were multilayers of $\mathrm{Cd}(\mathrm{II})$ ions formed on the adsorbent surface at equilibrium [30].

The value of the adsorption intensity $(n)$ which describes the surface site energy distribution was less than unity, which means adsorption occurred on predominantly heterogeneous adsorption sites [42]. The probability of an adsorbate finding a vacant adsorption site on the surface of the adsorbent during adsorption has been determined by the number of hopping (n) done by adsorbate ions [43]. Accordingly, the hopping number $(n)$ of $\mathrm{Cd}(\mathrm{II})$ ions on G-3 PAMAM SGA was correlated with an increase in adsorbate concentration and temperature (Figure 5). It was observed that the probability of adsorbate ions to find vacant adsorption sites on the adsorbent was highest when the initial concentration of adsorbate solution was $125 \mathrm{ppm}$ at $303 \mathrm{~K}$.

Increasing the ambient experimental temperature from 293 through $313 \mathrm{~K}$ (Figure 4) showed that temperature had a positive effect on the adsorption of Cd(II) ions on G-3 PAMAM SGA; thus, the adsorption process was also evaluated using the following thermodynamic parameters: enthalpy change $\left(\Delta H^{\circ}\right)$, entropy change $\left(\Delta S^{\circ}\right)$, Gibbs free energy $\left(\Delta G^{\circ}\right)$, sticking probability $\left(S^{*}\right)$, and activation energy $\left(E_{\mathrm{a}}\right)$. The aforementioned thermodynamic parameters were calculated from the experimental equilibrium data obtained at the various temperatures investigated using the modified Arrhenius equation and the parameters are shown in Table 4 . The $\Delta G^{\circ}$ values for all temperatures studied were negative, which presupposes a spontaneous and feasible adsorption process. The value of $\Delta H^{\circ}$ obtained from the calculation was positive which is an affirmation that the adsorption process was endothermic because, for typical endothermic processes, an increase in external energy would favour the forward process; accordingly, there was an increase in the uptake of $\mathrm{Cd}(\mathrm{II})$ ions with an increase in solution temperature [38]. The positive value of the $\Delta S^{\circ}$ is an indication of increased randomness of adsorbate ions in the solution as the adsorption process tends towards equilibrium. Although the calculated value for activation energy

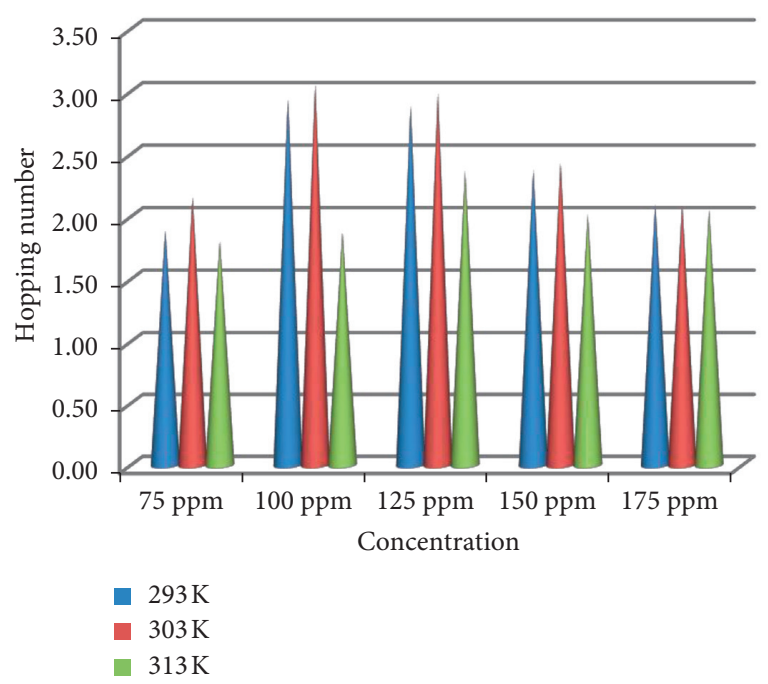

FIgURE 5: Correlating the initial concentration of Cd(II) ions with hopping number $(n)$ as operating temperature increased.

TABle 4: Thermodynamic parameters of G-3 PAMAM SGA for Cd(II) adsorption.

\begin{tabular}{lcc}
\hline Thermodynamic & Parameter & $\mathrm{Cd}(\mathrm{II})$ \\
\hline$\Delta H^{\circ}$ & $\mathrm{kJ} \mathrm{mol}^{-1}$ & 3.293 \\
$\Delta S^{\circ}$ & $\mathrm{J} \mathrm{mol}^{-1} \mathrm{~K}^{-1}$ & 0.0786 \\
& $293 \mathrm{~K}$ & -1.504 \\
$\Delta G^{\circ}\left(\mathrm{kJ} \mathrm{mol}^{-1}\right)$ & $303 \mathrm{~K}$ & -1.55 \\
& $313 \mathrm{~K}$ & -1.607 \\
\hline
\end{tabular}

$\left(E_{\mathrm{a}}\right)$ was low $\left(2.49 \times 10^{-3} \mathrm{kJmol}^{-1}\right)$ which is indicative of a diffusion-controlled adsorption process, its positive value is an additional evidence that the process was endothermic. Sticking probability, which is a function of adsorbate/adsorbent interactive system, was estimated to be approximately unity $\left(S^{*}=1.0003\right)$ which presupposes a linear sticking relationship between adsorbate ions and the adsorbent within a multilayered adsorption system. Thus, a possible combination of physisorption and chemisorption (cooperative adsorption) was presumed.

3.6. Regeneration and Reusability. Regeneration of previously used adsorbent and recovery of adsorbate ions are very crucial for improving sorption process economics since regeneration allows for repeated reuse of adsorbent material and in essence lowers cost. Results of three cycles of desorption tests were carried out on G-3 PAMAM SGA previously used for Cd(II) sequestration (see Table 5).

It can be inferred from Table 5 that the $3^{\text {rd }}$ cycle was slightly lower than the $2^{\text {nd }}$ by $12.95 \%$, while the $2^{\text {nd }}$ cycle was lower than the $1^{\text {st }}$ cycle by $25.24 \%$. The significant difference between the $1^{\text {st }}$ and $2^{\text {nd }}$ adsorption cycles could be attributed to insufficient vacant adsorption sites on the adsorbent after the $1^{\text {st }}$ adsorption cycle. The desorbing solvent could not reach the inner pores/crevices of the adsorbent material but desorbed adsorbate ions at the surface and near-surface regions of the adsorbent after the $1^{\text {st }}$ cycle. Thus, adsorbate 
Table 5: Efficiency of desorption of Cd(II) using $0.5 \mathrm{M} \mathrm{HNO}_{3}$.

\begin{tabular}{lc}
\hline Adsorption cycle & Desorption efficiency (\%) \\
\hline 1 & 85.59 \\
2 & 60.35 \\
3 & 47.40 \\
\hline
\end{tabular}

TABle 6: Comparison of G-3 PAMAM SGA Cd(II) adsorption capacity with some adsorbents reported in the literature.

\begin{tabular}{lcc}
\hline Adsorbent & $q_{\mathrm{e}}(\mathrm{mg} / \mathrm{g})$ & Reference \\
\hline Hematite & 4.94 & {$[37]$} \\
SBA-15 & 9.84 & {$[44]$} \\
Bentonite-Carica papaya composite & 10.9 & {$[45]$} \\
Feldspar-pine cone composite & 11.5 & {$[46]$} \\
Wheat stem & 11.6 & {$[47]$} \\
Chitin & 14.7 & {$[48]$} \\
G-3 PAMAM-SGA & 24.49 & This study \\
STNTS-Ch beads & 38.8 & {$[49]$} \\
Orange waste & 48.3 & {$[50]$} \\
G-5-PAMAM SGA & 123.4 & {$[30]$} \\
Nanocomposite material & 148.32 & {$[51]$} \\
Silica-activated carbon $(2: 3)$ & 178.5 & {$[52]$} \\
Activated sludge & 204.1 & {$[53]$} \\
Biogenic Mn oxide & 229.3 & {$[54]$} \\
\hline
\end{tabular}

ions that were initially adsorbed at the near-surface region of the adsorbent were not accessible at the $3^{\text {rd }}$ cycle and this resulted in a reduction in adsorption capacity by $12.95 \%$.

3.7. Comparison with Reported Adsorbents. The G-3 PAMAM SGA adsorption capacity for Cd(II) has been compared with some low-cost and silica-based adsorbents reported in the literature (Table 5). The comparison showed that the G-3 PAMAM SGA adsorbent performed better than a number of reported adsorbents for Cd(II) sequestration from aqueous solutions. The fact that the adsorption capacity of G-3 PAMAM SGA was comparable to some of the best performing adsorbents reported in the literature points to the prospective of this composite for the removal of $\mathrm{Cd}(\mathrm{II})$ from aqueous systems (Table 6).

\section{Conclusion}

Generation-3 polyamidoamine dendrimer was functionalized with amide and amine groups and immobilized on activated silica using 3-aminopropyltriethoxysilane (APTES) linkage to produce a G-3 PAMAM SGA composite. Characterization results for the synthesized composite show successful synthesis due to the observation of FTIR peaks attributable to amide functional groups $\left(1630 \mathrm{~cm}^{-1}\right)$ and moderately lower thermal stability when compared to pristine silica, which may be due to the presence of integrated moieties. SEM micrographs revealed irregular and heterogeneous surfaces of the composite before Cd(II) adsorption and the presence of agglomerated Cd(II) ions on the surface of the adsorbent after adsorption. Adsorption experiments showed an equilibration time of 180 minutes, an optimum $\mathrm{pH}$ of 5 , and an experimental adsorption capacity of $24.9 \mathrm{mg} \cdot \mathrm{g}^{-1}$. Thermodynamic studies showed that the process was endothermic, spontaneous, and feasible. Equilibrium and kinetic data modeling suggests electrostatic interactions between surface active sites and $\mathrm{Cd}$ (II) ions in solution and adsorption via pore-filling mechanism. The mechanism of Cd(II) and G-3 PAMAM SGA interaction is believed to follow a chelation/complexation of $\mathrm{Cd}$ (II) ions via coordination reactions between amide $(-\mathrm{NH}(\mathrm{CO}))$ - , amine (NH-R) groups, and $\mathrm{Cd}(\mathrm{II})$ ions. Pseudo-secondorder kinetic model described the experimental data best, signifying a chemisorption controlled process. Freundlich isotherm had the best fit to equilibrium data which is indicative of multilayered adsorption that occurred on heterogeneous surfaces. However, the Langmuir model had a good correlation with equilibrium data too with the highest adsorption capacity $\left(24.49 \mathrm{mg} \cdot \mathrm{g}^{-1}\right)$ which suggests some occurrences of physisorption as well. This assumption was clarified by the calculated value for sticking probability of the adsorption process, which is an evidence of a possible combination of physisorption and chemisorption (cooperative adsorption). G-3 PAMAM SGA demonstrated good reusability after three cycles of adsorption.

Hence, the modification procedure was successful and the synthesized composite (G-3 PAMAM SGA) could be efficient for the removal of $\mathrm{Cd}(\mathrm{II})$ ions from aqueous systems.

\section{Data Availability}

All data were generated at Applied Chemistry and Nanoscience Laboratory, Department of Chemistry, Vaal University of Technology, Vanderbijlpark, South Africa, and Department of Chemical Sciences, Niger Delta University, Wilberforce Island, Nigeria.

\section{Conflicts of Interest}

The authors declare that there are no conflicts of interest.

\section{References}

[1] M. Ajmal, A. Mohammad, R. Yousuf, and A. C. Ahmad, "Adsorption behavior of cadmium, zinc, nickel and lead from aqueous solutions by magnifera indica seed shell.India," Journal of Environmental Health, vol. 40, pp. 15-26, 1998.

[2] E. Valdman, L. Erijman, F. L. P. Pessoa, and S. G. F. Leite, "Continuous biosorption of $\mathrm{Cu}$ and $\mathrm{Zn}$ by immobilized waste biomass Sargassum sp," Process Biochemistry, vol. 36, no. 8-9, pp. 869-873, 2001.

[3] P. B. Tchnounwou, C. G. Yedjou, A. K. Patlolla, and D. J. Sutton, "Molecular, clinical and environmental toxicology," Experientia Supplimemtum, vol. 101, p. 133, 2012.

[4] G. Ellen, J. W. Loon, and K. Tolsma, "Heavy metals in vegetables grown in The Netherlands and in domestic and imported fruits," Zeitschrift for Lebensmittel-Untersuchung undForschung, vol. 190, no. 1, pp. 34-39, 1990.

[5] J. O. Duruibe, M. O. C. Oguebu, and J. N. Egwurugow, "Heavy metal pollution and human biotoxic effects," International Journal of Physical Sciences, vol. 2, pp. 112-118, 2007. 
[6] J. R. Gabarino, H. Heyes, D. Roth, R. Antweider, T. I. Brinton, and H. Taylor, Contaminants in the Mississipi River, p. 46, U.S. Geological Survey Circular, Virginia, NV, USA., 1995.

[7] D. McCluggage, Heavy Metal Poisoning, NCS Magazine. The Bird Hospital, Columbus, 1991, http://www.cocicaties.org/ articles/diseases/metals.html.

[8] M. O. Ogwuegbu and M. A. Ijioma, "Effects of certain heavy metals on the population due to mineral exploitation," in Proceedings of the International Conference on Scientific and Environmental Issues in the Population, Environment and Sustainable Development in Nigeria, pp. 8-10, University of Ado Ekiti, Ado Ekiti, Nigeria, 2003.

[9] M. Tezo, "Biosorpttion of metals; the experience accumulated and the outlook for technology development," Hydrometallurgy, vol. 59, pp. 241-243, 2001.

[10] B. R. Singh and M. J. McLaughling, "Cadmium in soils and plants," in Developments in Plants and Soil Sciences, M. J. McLaughlin and B. R. Singh, Eds., pp. 257-268, Kluwer Publishers, Dordrecht, Netherlands, 1999.

[11] S. Stohs and D. Bagchi, "Oxidative mechanisms in the toxicity of metal ions," Free Radical Biology and Medicine, vol. 18, no. 2, pp. 321-336, 1995.

[12] R. S. Mitra, "Protein synthesis in Escherichia coli during recovery from exposure to low levels of $\mathrm{Cd} 2+$, , Applied and Environmental Microbiology, vol. 47, no. 5, pp. 1012-1016, 1984.

[13] S. K. Gunatilake, "Methods for removing heavy metals from industrial wastewater," Journal of Multidisciplinary Engineering Science Studies (JMESS), vol. 1, pp. 12-18, 2015.

[14] P. N. E. Diagboya and E. D. Dikio, "Silica-based mesoporous materials; emerging designer adsorbents for aqueous pollutants removal and water treatment," Microporous and Mesoporous Materials, vol. 266, pp. 252-267, 2018.

[15] A. Ma, A. Abushaikha, S. J. Allen, and G. McKay, "Ion exchange homogeneous surface diffusion modelling by binary site resin for the removal of nickel ions from wastewater in fixed beds," Chemical Engineering Journal, vol. 358, pp. 1-10, 2019.

[16] A. Eser, V. Nüket Tirtom, T. Aydemir, S. Becerik, and A. Dinçer, "Removal of nickel(II) ions by histidine modified chitosan beads," Chemical Engineering Journal, vol. 210, pp. 590-596, 2012.

[17] K. Wu, L. Luan, J. Xing et al., "Removal of Zn(II) and Co(II) from N,N-dimethylformamide by polyamidoamine dendrimers decorated silica: performance and mechanism," Journal of Molecular Liquids, vol. 308, Article ID 113073, 2020.

[18] Y. Yuan, Y. Wu, H. Wang et al., "Simultaneous enrichment and determination of cadmium and mercury ions using magnetic PAMAM dendrimers as the adsorbents for magnetic solid phase extraction coupled with high performance liquid chromatography," Journal of Hazardous Materials, vol. 386, Article ID 121658, 2020.

[19] B. Hayati, A. Maleki, F. Najafi et al., "Heavy metal adsorption using PAMAM/CNT nanocomposite from aqueous solution in batch and continuous fixed bed systems," Chemical Engineering Journal, vol. 346, pp. 258-270, 2018.

[20] M. S. Podder and C. B. Majumder, "Biosorption of As(III) and $\mathrm{As}(\mathrm{V})$ on the surface of TW/MnFe2O4 composite from wastewater: kinetics, mechanistic and thermodynamics," Applied Water Science, vol. 7, no. 6, pp. 2689-2715, 2017.

[21] T. S. Kazeem, S. A. Lateef, S. A. Ganiyu et al., "Aluminiummodified activated carbon as efficient adsorbent for cleaning of cationic dye in wastewater," Journal of Cleaner Production, vol. 205, pp. 303-312, 2018.

[22] R. G. Acres, A. V. Ellis, J. Alvino et al., "Molecular structure of 3-Aminopropyltriethoysilane layers formed on silanol-terminated Silicon surfaces," The Journal of Physical Chemistry A, vol. 116, pp. 689-697, 2012.

[23] Y. Jiang, Q. Gao, H. Yu, Y. Chen, and F. Deng, "Intensively competitive adsorption for heavy metal ions by PAMAMSBA-15 and EDTA-PAMAM-SBA-15 inorganic-organic hybrid materials," Microporous and Mesoporous Materials, vol. 103, no. 1-3, pp. 316-324, 2007.

[24] X. Shi, K. Sun, P. L. Balogh, and R. J. Baker Jr., "Synthesis, characterization, and manipulation of dendrimer-stabilized iron sulfide nanoparticles," Nanotechnology, vol. 17, 2006.

[25] H. O. C. Emeka-Okorie, P. N. Ekemeie, K. G. Akpomie, and C. S. Olikagu, "Calcined corncob-kaolinite combo as new sorbent for sequestration of toxic metal ions from polluted aqua media and desorption," Frontiers in Chemistry, vol. 6, 2018.

[26] S. Lagergren, R. G. Acres, A. V. Ellis et al., "Handlingar," The Journal of Physical Chemistry C, vol. 116, pp. 6289-6297, 2012.

[27] S. Lagergren, "Zur theorie der sogenannten adsorption geloster stoffe. Kungliga svenska vetenskapsakademiens," Handlingar, vol. 24, pp. 1-39, 1898.

[28] W. J. Weber and J. C. Morris, "Advances in water pollution research: removal of biologically resistant pollutant from wastewater by adsorption," in Proceedings of the 1st International Conference on Water Pollution Symposium, pp. 231-266, Pergamon Press, Jerusalem, Israel, 1962.

[29] I. Langmuir, "The constitution and fundamental properties of solids and liquids. Part I. Solids," Journal of the American Chemical Society, vol. 38, no. 11, pp. 2221-2295, 1916.

[30] N. Ayawei, A. N. Ebelegi, and D. Wankasi, "Modelling and interpretation of adsorption isotherms," Journal of Chemistry, vol. 2017, Article ID 3039817, 11 pages, 2017.

[31] N. A. Ebelegi, A. K. Inengite, N. Ayawei, and D. Wankasi, "modeling of adsorption isotherms for methylene blue sorption onto fly ash modified with hydrochloric acid," Journal of Chemical Science and Technology, vol. 6, no. 1, pp. 1-9, 2017.

[32] A. Penkova, J. M. Martínez Blanes, S. A. Cruz, M. A. Centeno, K. Hadjiivanov, and J. A. Odriozola, "Gold nanoparticles on silica monospheres modified by amino groups," Microporous and Mesoporous Materials, vol. 117, no. 3, pp. 530-534, 2009.

[33] A. N. Ebelegi, N. Ayawei, D. Wankasi, E. D. Dikio, P. N. Diagboya, and F. N. Mtunzi, "Covalently bonded Polyamidoamine functionalized silica used as a $\mathrm{Pb}$ (II) scavenger from aqueous solution," Journal of Environmental Chemical Engineering, vol. 7, pp. 1-8, Article ID 103214, 2019.

[34] C. Y. Abasi, P. N. E. Diagboya, and E. D. Dikio, "Synthesis, characterization of ternary layered double hydroxides (LDH) for sorption kinetics and thermodynamics of $\mathrm{Cd}^{2+}$," International Journal of Environmental Studies, vol. 76, no. 3, pp. 441-455, 2019.

[35] E. Repo, J. K. Warchoł, A. Bhatnagar, and M. Sillanpää, "Heavy metals adsorption by novel EDTA-modified chitosansilica hybrid materials," Journal of Colloid and Interface Science, vol. 358, no. 1, pp. 261-267, 2011.

[36] P. N. Diagboya, B. I. Olu-Owolabi, and K. O. Adebowale, "Microscale scavenging of pentachlorophenol in water using amine and tripolyphosphate-grafted SBA-15 silica: batch and modeling studies," Journal of Environmental Management, vol. 146, pp. 42-49, 2014. 
[37] B. I. Olu-Owolabi, A. H. Alabi, E. I. Unuabonah, P. N. Diagboya, L. Böhm, and R.-A. Düring, "Calcined biomass-modified Bentonite clay for removal of aqueous metal ions," Journal of Environmental Chemical Engineering, vol. 4, no. 1, pp. 1376-1382, 2016.

[38] P. N. Diagboya, B. I. Olu-Owolabi, E. D. Dikio, and K. O. Adebowale, "Concentration dependent and simultaneous sorption and desorption of pyrene and fluorine on major soil minerals in sub-saharan Africa," Applied Clay Science, vol. 153, pp. 253-264, 2018.

[39] C. Y. Abasi, P. N. E. Diagboya, and E. D. Dikio, "Layered double hydroxide of cobalt-zinc-aluminium intercalated with carbonate ion: preparation and $\mathrm{Pb}(\mathrm{II})$ ion removal capacity," International Journal of Environmental Studies, vol. 76, no. 2, p. 251, 2018.

[40] E. D. Asuquo and A. D. Martin, "Sorption of cadmium (II) ion from aqueous solution onto sweet potato (Ipomoea batatas L.) peel adsorbent: characterisation, kinetic and isotherm studies," Journal of Environmental Chemical Engineering, vol. 4, no. 4, pp. 4207-4228, 2016.

[41] A. N. Ebelegi, J. Godwin, N. Ayawei, and D. Wankasi, "Facile uptake of cadmium (II) from aqueous solution using polyamidoamine functionalized silica," Journal of Environmental Analytical Chemistry, vol. 6, pp. 2380-2391, 2019.

[42] N. A. Ebelegi, S. S. Angaye, N.. Ayawei, and D. Wankasi, "Removal of Congo Red from aqueous solutions using fly ash modified with hydrochloric acid," British Journal of Science and Technology, vol. 20, no. 2, pp. 1-7, 2017.

[43] M. C. Menkiti, M. C. Aneke, P. M. Ejikeme, O. D. Onukwuli, and N. U. Menkiti, "Adsorptive treatment of brewery effluent using activated chrysophyllum albidum seed shell carbon," Springerplus, vol. 213, pp. 1-19, 2014.

[44] D. B. Singh, D. C. Rupainwar, G. Prasad, and K. C. Jayaprakas, "Studies on the Cd(II) removal from water by adsorption," Journal of Hazardous Materials, vol. 60, no. 1, pp. 29-40, 1998.

[45] Q.-Z. Zhai and X.-D. Li, "Efficient removal of cadmium (II) with SBA-15 nanoporous silica: studies on equilibrium isotherm, kinetics and thermodynamics," Applied Water Science, vol. 9, pp. 1-11, 2019.

[46] G. Tan and D. Xiao, "Adsorption of cadmium ion from aqueous solution by ground wheat stems," Journal of Hazardous Materials, vol. 164, no. 2-3, pp. 1359-1363, 2009.

[47] B. Benguella and H. Benaissa, "Cadmium removal from aqueous solutions by chitin: kinetic and equilibrium studies," Water Research, vol. 36, no. 10, pp. 2463-2474, 2002.

[48] P. N. Diagboya and E. D. Dikio, "Scavenging of aqueous toxic organic and inorganic cations using novel facile magnetocarbon black-clay composite adsorbent," Journal of Cleaner Production, vol. 180, pp. 71-80, 2018.

[49] R. Quiroga-Flores, A. Noshad, R. Wallenberg, and L. Oonby, "Adsorption of cadmium by a high capacity adsorbent composed of silicate-titanate nanaotubes embedded in hydrogel chitosan beads," Environmental Technology, vol. 41, pp. 3034-30554, 2020.

[50] A. B. Pérez-Marín, V. M. Zapata, J. F. Ortuño, M. Aguilar, J. Sáez, and M. Lloréns, "Removal of cadmium from aqueous solutions by adsorption onto orange waste," Journal of Hazardous Materials, vol. 139, no. 1, pp. 122-131, 2007.

[51] M. Kanib, A. Kabbani, H. Holail, and Z. Olama, "Heavy metals removal using activated carbon, silica and silica activated carbon composite," Energy Procedia, vol. 50, pp. 113-120, 2014.

[52] D. R. Awual, M. Khraisheh, N. .. Alhathi et al., "Efficient detection and adsorption of $\mathrm{Cd}(\mathrm{II})$ ions using innovative nano-composite materials," Chemical Engineering Journal, vol. 343, pp. 118-127, 2018.

[53] R. D. C. Soltani, A. J. Jafari, and G. S. Khorramabadi, "Investigation of cadmium (II) ions biosorption onto pretreated dried activated sludge," American Journal of Environmental Sciences, vol. 5, pp. 41-46, 2009.

[54] Y.-T. Meng, Y.-M. Zheng, L.-M. Zhang, and J.-Z. He, "Biogenic $\mathrm{Mn}$ oxides for effective adsorption of $\mathrm{Cd}$ from aquatic environment," Environmental Pollution, vol. 157, no. 8-9, pp. 2577-2583, 2009. 